\title{
Loss of High-Frequency Brain Electrical Response to Thiopental Administration in Alzheimer's-Type Dementia
}

Daniel P. Holschneider, M.D., Andrew F. Leuchter, M.D., Sebastian H. J. Uijtdehaage, Ph.D., Michelle Abrams, R.N., and Susan Rosenberg-Thompson, R.N., M.N., C.

Abnormal brain regions generate proportionately less highfrequency (beta) activity than nonpathological regions, a phenomenon accentuated by barbiturate administration. Using quantitative electroencephalography we examined power in the 20- to 28- $\mathrm{Hz}$ band in patients with dementia of the Alzheimer's type (DAT), vascular dementia $(V a D)$, and normal elderly controls (CON) following an IV bolus of thiopental $(0.5 \mathrm{mg} / \mathrm{kg})$. Compared to both CON and $V a D$ subjects, DAT subjects showed a marked loss of beta power elicited across the cortex, with largest differences noted in the frontal region. Losses were most significant for the peak response recorded at 30 to $90^{\circ} \mathrm{s}$ postinjection and persisted during the 5-minute follow-up period. We hypothesize that differences in this electrocerebral response reflect differences in the underlying neuropathology of DAT and VaD subjects. A thiopental challenge may be well suited for the in vivo assessment of brain function in dementias characterized by prominent cortical pathology.

[Neuropsychopharmacology 16:269-275, 1997] (C) 1997 American College of Neuropsychopharmacology
KEY WORDS: EEG; Thiopental; Alzheimer's disease; Vascular dementia; Beta activity

Brain dysfunction causes characteristic shifts in the production of brain electrical activity. A robust association exists between increased slow-wave activity on the electroencephalogram (EEG) and brain lesions. In addition, pathological decreases in high-frequency (beta) activity also have been reported commonly. Generalized reductions of beta frequencies have been consistently reported in patients with dementia (Duffy et al. 1984; Visser et al. 1985; Brenner, et al. 1986; Holschneider and Leuchter 1995). Despite a high specificity, however, the low sen-

From the Department of Psychiatry and Biobehavioral Sciences, University of California at Los Angeles School of Medicine, and the West Los Angeles Veterans Administration Medical Center, Los Angeles, CA.

Address correspondence to: Daniel P. Holschneider, M.D., UCLA Neuropsychiatric Institute, 760 Westwood Plaza, Los Angeles, CA 90024.

Received June 9, 1996; revised September 23, 1996; accepted September $25,1996$. sitivity of beta activity obtained with patients in the resting state has constrained the clinical utility of this measure in distinguishing pathological changes from those of normal aging (Coben et al. 1983). Although it has not been extensively studied in patients with dementia, it appears that pharmacological activation of the brain highlights the increased loss of beta activity (Letemendia and Pampiglione 1958). We report the first quantitative electroencephalographic (QEEG) study comparing thiopental activation in subjects with dementia of the Alzheimer's type (DAT) to those with vascular dementia (VaD), as well as to controls (CON).

In the normal human brain, prenarcotic dosages of barbiturates produce an abrupt onset of fast activity with an initial predominant frequency in the 20- to 28$\mathrm{Hz}$ range, with progression to slower frequencies at higher dosages in the anesthetic stage (Brazier and Finesinger 1945; Kiersey et al. 1951; Pampiglione 1952; Bickford 1953). The fast activity of the prenarcotic stage is seen most robustly in the frontal regions, spreading gradually (and with lower amplitude) more posteriorly. 
Work with deeply implanted electrodes (Brazier et al. 1956; Engel et al. 1982) has demonstrated that this effect is at the level of the cell bodies and is a reaction of all normal neurons. As early as in the 1950s, Alema and Sinisi (1950) and later Pampiglione (1952) found that these barbiturate-induced rhythms were reduced over areas of damage and aided in localizing lesions. Later Shagass et al. used changes in induced EEG fast frontal activity to assess the balance between excitatory and inhibitory influences on the cortex as they relate to a variety of psychiatric diagnoses (Shagass 1953; Claridge and Herrington 1963). Depth electrode studies have compared barbiturate-induced beta activity in epileptogenic and nonepileptogenic mesiotemporal regions and have shown relatively less fast activity in the pathological temporal lobe (Lombroso and Erba 1970; Lieb et al. 1974; Engel et al. 1981; Lieb et al. 1986).

Thiopental has not been consistently useful in localizing focal neuronal pathology. Lieb et al. (1989) have suggested that reductions in barbiturate-induced beta activity may reflect the lack of a normal response to a drug challenge by the cells remaining in that region rather than the absolute number of cells that have survived. Such an abnormal response might, for example, be a consequence of pathological alterations in receptor sites, intrinsic cellular functioning, or circuitry of the remaining cells. We propose that a thiopental challenge may be particularly well suited for the in vivo assessment of brain function in subjects with dementia, precisely because these disorders are characterized by global, rather than focal, neuronal dysfunction. We hypothesize that differences in the neuropathology of DAT, $\mathrm{VaD}$, and CON subjects will be reflected as differences in their high-frequency response to a barbiturate challenge.

\section{METHODS}

\section{Patients}

We evaluated 8 subjects with DAT, 6 subjects with $\mathrm{VaD}$, and 8 normal elderly controls (CON) of comparable average age and gender ratios (DAT: $75.3 \pm 9.0$ years, F:M 1:1; VaD: $78.4 \pm 7.8$ years, F:M 2:1; CON: $74.3 \pm 8.9$ years, F:M 3:1). Subjects with dementia showed greater cognitive impairment as measured by Folstein MMSE scores (Folstein et al. 1975) than control subjects (DAT: $16.5 \pm 10.5$; VaD: $17.8 \pm 6.1$; CON: $29.0 \pm 1.0$, respectively). DAT subjects were diagnosed according to DSM-IIIR criteria (APA 1987) for primary degenerative DAT and were required to satisfy the McKhann et al. (1984) criteria of "probable Alzheimer's disease." VaD subjects were diagnosed according to DSM-IIIR criteria for multi-infarct dementia (MID) and were required to have a Hachinski score of 7 or greater or show evidence of infarction or ischemic changes on MRI. Control and DAT subjects showed low Hachinski ischemia scores
(Hachinski et al. 1974) compared to VaD subjects (DAT: $2.2 \pm 1.6 ; \mathrm{VaD} 7.2 \pm 1.3 ; \mathrm{CON}: 0.2 \pm 0.4)$. Subjects were free of any psychotropic medications, including overthe-counter medications for at least 14 days prior to their EEGs. Informed consent was obtained in accordance with the guidelines of the UCLA Human Subjects Protection Committee.

MRI scans were performed on all subjects within 1 year of their EEGs. CON subjects showed no or minimal evidence of any deep white matter disease or atrophy. DAT subjects showed mild to moderate atrophy with minimal deep white matter disease, whereas $\mathrm{VaD}$ subjects presented moderate to extensive small-vessel ischemic disease or exhibited evidence of an old stroke.

\section{QEEG Recording}

EEGs were performed at the UCLA Neuropsychiatric Hospital QEEG Laboratory using standard clinical procedures (Leuchter et al. 1993), with electrodes applied according to the International 10-20 System. Recordings were obtained using a $\mathrm{Pz}$ reference. Eye movements were monitored using anterior scalp electrodes and a right infraorbital electrode. Brain electrical activity was recorded using a QND electroencephalograph (Neurodata, Pasadena, CA) with a digital sampling rate of 256 points/channel/s with frequency filter settings of 0.5 and $70 \mathrm{~Hz}$. Subjects were alerted every $30 \mathrm{~s}$ or more frequently if drowsiness was detected. From each subject, 5 minutes of artifact-free EEG data were obtained on paper and computer disc prior to thiopental administration in the eyes-closed, maximally alert waking state. An injection of $0.5 \mathrm{mg} / \mathrm{kg}$ sodium thiopental (volume $1.29 \pm 0.8 \mathrm{ml}$ ) followed by a $2-\mathrm{ml}$ flush of $0.5 \mathrm{~N}$ saline was given by rapid IV bolus (Oldendorf et al. 1965). The onset of an electrographic response to thiopental was seen within the first $30 \mathrm{~s}$ of administration in all cases, with maximum high-frequency activity seen at 60 to $90 \mathrm{~s}$, as has previously been reported (Duffy et al. 1984; Dierks et al. 1992).

\section{Data Analysis}

The first eight 4-s epochs (a total of $32 \mathrm{~s}$ ) of artifact-free data during the 1-minute period immediately preceding thiopental injection were selected and averaged to obtain a frequency spectrum at baseline for that individual. Thirty seconds after infusion, eight 4-s epochs were similarly selected within each 1-minute interval over 5 minutes. Data were reformatted off-line to a bipolar montage and spectral analysis of the data was performed using a discrete Fourier transformation. Numerical values of power were obtained in the $20-28 \mathrm{~Hz}$ frequency range, previously reported to demonstrate the most robust thiopental response (Brazier and Finesinger 1945; Kiersey et al. 1951; Pampiglione 1952; Bickford 1953). Power values were log-transformed to avoid problems with skewness and kurtosis (Leuchter et al. 1993) and 
then were subtracted from baseline values to obtain the thiopental response for each individual. Statistical analysis was performed for combined electrode pairings from eight brain regions: (1) left frontal, F1-F3 + F1-F7; (2) left frontotemporal, F7-T3 + T3-T5; (3) left central-parietal, F3-C3 + C3-P3; (4) left temporo-parieto-occipital, $\mathrm{T} 5-\mathrm{O} 1+\mathrm{P} 3-\mathrm{O} 1 ;$ (5) right frontal, F2-F4 + F2-F8; (6) right frontotemporal, F8-T4 + T4-T6; (7) right centralparietal, F4-C4 + C4-P4; and (8) right temporo-parieto-occipital, $\mathrm{T} 6-\mathrm{O} 1+\mathrm{P} 4-\mathrm{O} 2$. A univariate repeatedmeasures analysis of variance (ANOVA) was performed for the peak response during the first minute interval, using hemisphere and region as within-subject factors. Post hoc Scheffe's test was used to examine group differences across different brain regions.

\section{RESULTS}

The EEG peak response to the barbiturate in all subject groups was most robust in frontal and central regions during the first minute interval. Figure 1 shows topographic changes of brain electrical power $\left(\mathrm{mV}^{2}\right)$ in the $20-$ to $28-\mathrm{Hz}$ frequency band at peak response in the first minute interval following an IV bolus of thiopental. Depicted are the group averages of $\log$ (power), in which each subject's postinjection EEG power was subtracted from its baseline value. Compared to both CON and $\mathrm{VaD}$ subjects, DAT subjects showed a marked loss of the peak increase in beta power in the $20-$ to $28-\mathrm{Hz}$ band following drug infusion. DAT compared to both CON and $\mathrm{VaD}$ subjects demonstrated a loss of drug-induced beta power in frontal regions (left frontal, F1-F3 + F1-F7; right frontal, F2-F4 + F2-F8), as well as globally. A scatterplot of the peak thiopental responses for individuals within each group is shown in Figure 2. Changes in $\log$ (power) in the $20-$ to $28-\mathrm{Hz}$ band were smaller for DAT subjects compared to CON and VaD subjects, particularly in the left frontal region.

The changes in $\log$ (power) in the bilateral frontal regions for five 1-minute intervals following thiopental
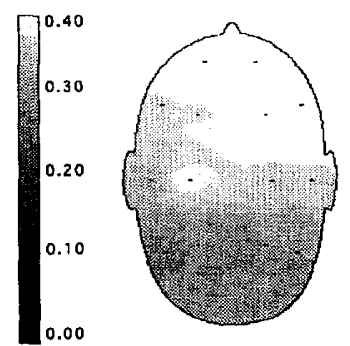

CON

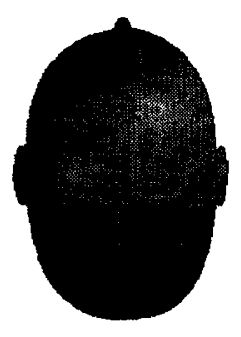

DAT

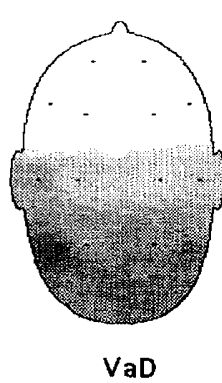

VaD
Figure 1. Topographic changes in brain electrical power $\left(\log _{10}, \mu \mathrm{V}^{2}\right)$ in the 20- to $28-\mathrm{Hz}$ band during the first minute interval after thiopental bolus injection averaged for $\mathrm{CON}$, DAT, and VaD subjects. infusion are shown in Figures 3A and 3B. The evolution of the high-frequency response showed a decrement over time for each subject group. DAT subjects showed an attenuated peak response during the initial 2 minutes following drug infusion, with progressive losses in beta power as high-frequency power was rapidly replaced by slow-wave power. The beta response of DAT subjects appeared more robust over the right frontal region, whereas that of $\mathrm{CON}$ and $\mathrm{VaD}$ subjects showed a similar bilateral response.

A univariate repeated-measures ANOVA showed a significant difference in thiopental response across groups $(f=4.35 ; \mathrm{df}=2,19 ; p<.05)$, with significant differences noted by brain region $(f=3.85 ; \mathrm{df}=3,57 ; p<$ $.05)$, but not by hemisphere. Interaction of group by region was significant $(f=2.54 ; \mathrm{df}=6,57 ; p<.05)$, indicating a difference in the regional thiopental response across diagnoses. The interaction of group by hemisphere by brain region was not significant. Post hoc Scheffe's test $(p<.05)$ showed significant differences in the left $(f=12.6 ; \mathrm{df}=2,19)$ and right $(f=6.9 ; \mathrm{df}=2,19)$

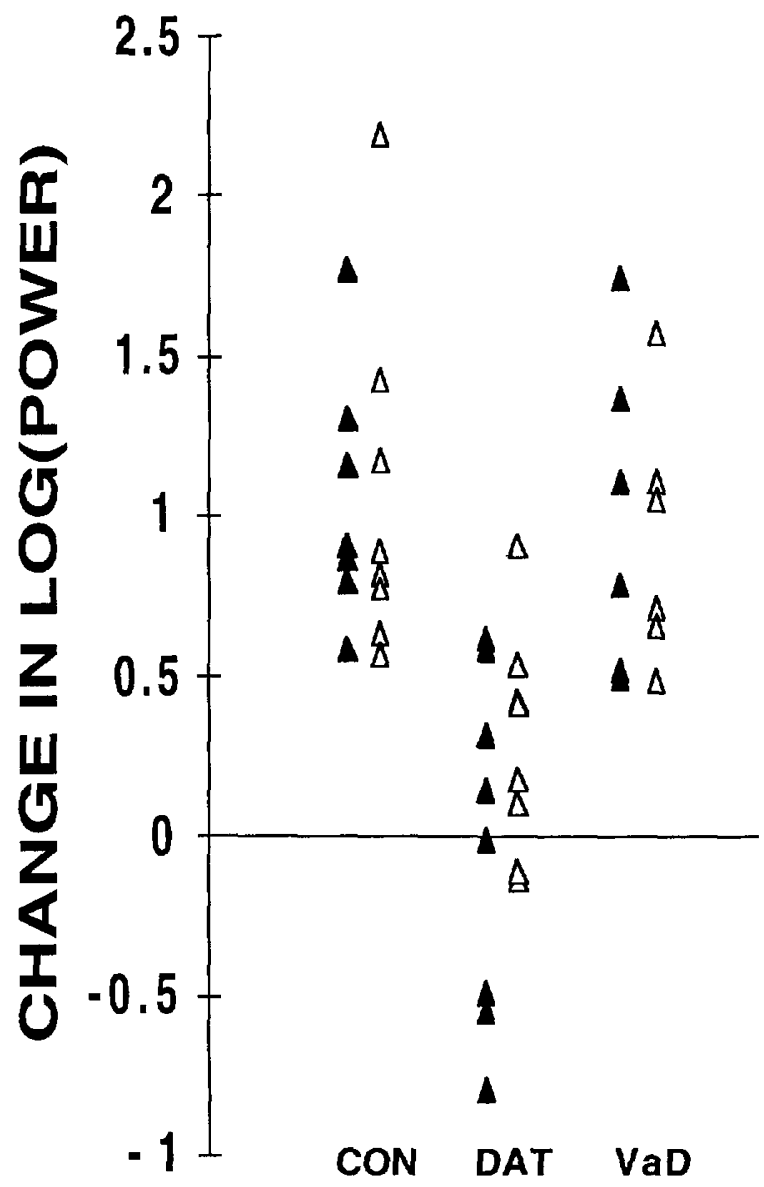

Figure 2. Changes in brain electrical power $\left(\log _{10}, \mu V^{2}\right)$ during the first minute interval after thiopental bolus injection in the 20- to $28-\mathrm{Hz}$ band in the left (solid triangles) and right (open triangles) frontal region for each subject of the CON, DAT, and VaD groups. 

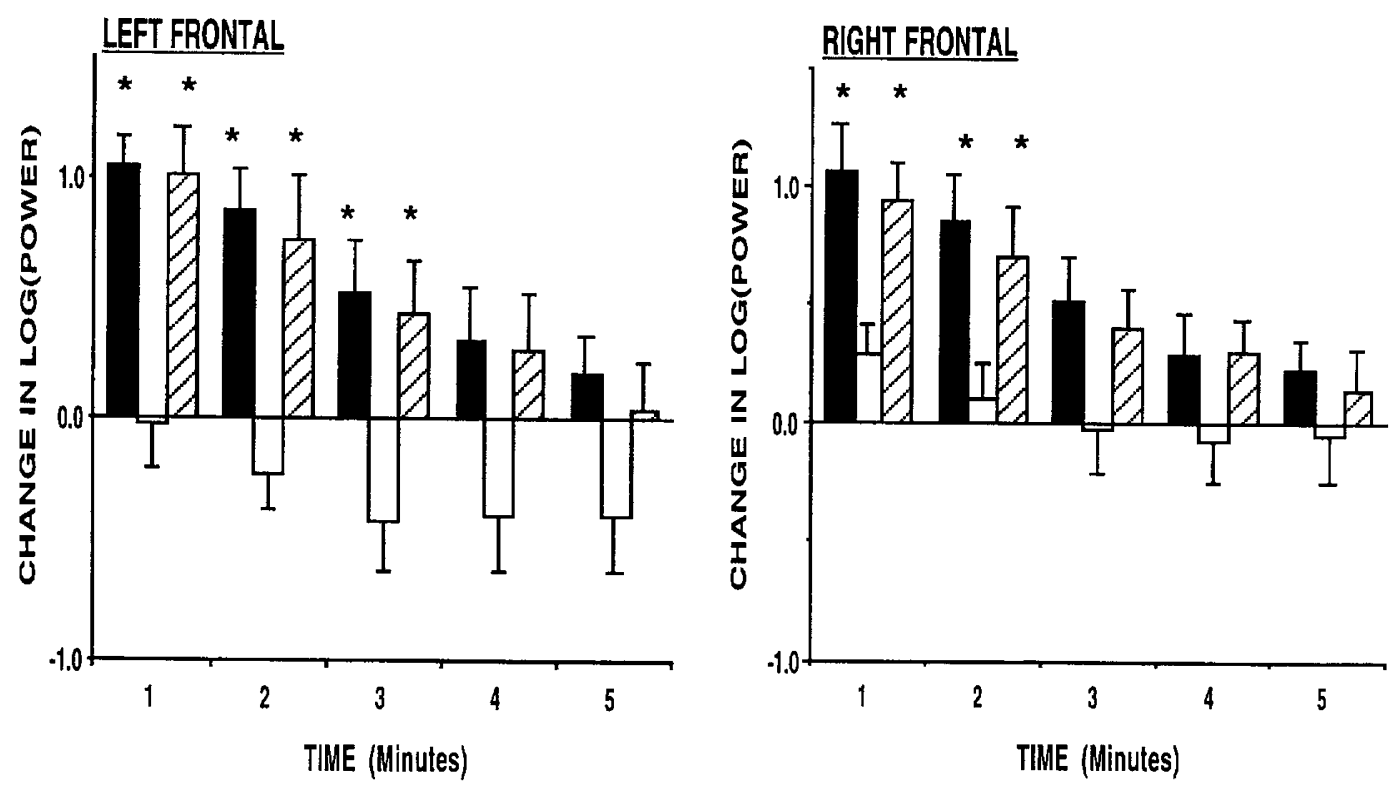

Figure 3. Changes in $\log _{10}$ power; $\left(\mu \mathrm{V}^{2}, 20-28 \mathrm{~Hz}\right)$ over time in the left and right frontal regions after thiopental administration for CON (solid bars), DAT (open bars), and VaD (cross-hatched bars) subjects. Error bars represent one standard error. *Significant differences with respect to DAT subjects $(p<.01)$.

frontal regions for DAT subjects compared to both CON and $\mathrm{VaD}$ subjects. No significant difference was noted between $\mathrm{CON}$ and $\mathrm{VaD}$ subjects.

At baseline, analysis of $\log$ (power) in the 20- to 28$\mathrm{Hz}$ band showed no significant difference between groups. As previously reported (Holschneider and Leuchter 1995), $\mathrm{DAT}$ and $\mathrm{VaD}$ subjects tended to show lower beta power across most head regions with losses in central and parietal areas noted in DAT subjects.

\section{DISCUSSION}

Loss of beta power has been consistently reported in dementia. The clinical utility of this observation, however, has been constrained by the low sensitivity of this measure in detecting brain dysfunction in patients during the resting state. This study showed that following pharmacological activation with thiopental, DAT subjects had a higher loss of the peak increase in electrocortical beta power than both $\mathrm{CON}$ and $\mathrm{VaD}$ subjects, particularly in the frontal region. $\mathrm{CON}$ and $\mathrm{VaD}$ subjects did not differ significantly in their electroencephalographic high-frequency response.

Beta activity elicited during our thiopental challenge represented more than simply an amplification of differences observed during the resting state. Past studies have shown that DAT subjects, compared to normal elderly during the resting state, demonstrate modest losses of beta activity, particularly in central and parietal regions (Prichep et al. 1983; Brenner et al. 1986; Saletu et al.
1991; Holschneider and Leuchter 1995). In the present study, similar differences in beta power were seen at baseline between DAT and CON subjects, although they did not reach statistical significance due to our small sample size. During the barbiturate challenge, however, losses were clearly discernible and appeared with greatest prominence in a frontal distribution. Furthermore, our current study showed that a barbiturate challenge reveals differences in high-frequency activity not seen at baseline between DAT and $\mathrm{VaD}$ subjects (Holschneider and Leuchter 1995).

The etiology of a decrease in the barbiturate-induced high-frequency response is not clearly understood. Depth recordings of the EEG during light pentothal anesthesia suggest that the generators of fast waves are cortical in location (unlike the activity recorded at deeper anesthetic levels) (Brazier et al. 1956). Histopathological studies in subjects with DAT strongly suggest a selective loss of large pyramidal cells whose axons form corticocortical connections between higher-order association areas (Terry et al. 1981; Hansen et al. 1988). This deafferentation, which has been described as a neocortical dysconnection syndrome (Morrison et al. 1990; Leuchter et al. 1992), may play a role in the decreased beta activity seen in DAT. We hypothesize that in VaD, often characterized by greater deep white matter ischemic disease and subcortical dysfunction (Román 1985, 1987; Lotz et al. 1986; Ferszt et al. 1987; Wallin and Blennow 1991), the thiopental response is less affected than in DAT with its propensity toward cortical degeneration.

The lack of a robust beta response of DAT patients during drug infusion may indicate that dysfunctional 
cortical neurons demonstrate a limited "reserve" to withstand physiological changes accompanying barbiturate infusion. These physiological changes include decreases in cerebral blood flow (Selman et al. 1982; Giswold and Steen 1985; Shapiro 1985) and cerebral metabolism (Blacklock 1987) that may occur even at preanesthetic doses of thiopental (Crane et al. 1978). That a loss of beta activity is correlated with decreases in cerebral blood flow and cerebral metabolism has been suggested by studies using positron emission tomography (PET) in patients with strokes (Nagata et al. 1989).

Likewise, a loss of a high-frequency response may indicate that dysfunctional cortical neurons demonstrate a limited ability to withstand increases in inhibitory neuronal activity reported during barbiturate administration (Schulz and Macdonald 1981; Harris and Allan 1985). Gamma aminobutyric acid (GABA) is the major inhibitory neurotransmitter of the cerebral cortex and its actions are facilitated by barbiturates. Though cortical GABAergic neurons appear relatively preserved in Alzheimer's patients (Meyer et al. 1995), it is possible that a loss in postsynaptic cells, including pyramidal cells, may be detectable on EEG following activation with a GABAergic agonist. Alternatively, reductions in cholinergic function demonstrated in DAT subjects (Coyle et al. 1983) may modulate the thiopental response of cortical GABAergic neurons that normally receive a rich cholinergic synaptic input (Beaulieu and Somogyi 1991).

The lack of a significant difference in the thiopental response of $\mathrm{VaD}$ patients and normal elderly subjects in our study was unexpected. This may reflect that our $\mathrm{VaD}$ patients had sufficiently intact cortical function to generate high-frequency activity at the dose of thiopental used in this experiment. Differences may be revealed in future dose-response studies.

Limitations inherent to this and most investigations of activity in the beta band include the possible confounding factors of muscle artifact (Oken 1986) and state dependency of the subject. Although we excluded epochs showing any sign of muscle artifact from analysis, and subjects were repeatedly alerted during the recording procedure, the occurrence of subtle eye movement artifact or brief moments of intermittent drowsiness cannot fully be excluded. Our sample size is small and further study using larger numbers of patients is indicated to test the specificity and sensitivity of our findings. DAT and $\mathrm{VaD}$ subjects in this study had moderate to moderately severe impairment. Further investigation is needed to evaluate the applicability of our findings to patients with earlier stages of dysfunction.

In summary, following thiopental administration DAT subjects showed a marked loss of the peak increase in beta power in the frontal region compared to both $\mathrm{CON}$ and $\mathrm{VaD}$ subjects. Unmasking the inability of diseased neurons to mount an adequate electrophysiological response during pharmacological challenge may be applicable to the characterization of dementias showing prominent cortical dysfunction.

\section{ACKNOWLEDGMENTS}

We gratefully acknowledge the assistance of Suzanne Hodgkin, R. EEG. T., and Mariahn Smith, R. EEG. T., who recorded the EEG data, as well as Ms. Jennifer Coxson for her preparation of this manuscript. This work was supported by Research Grant MH40705 and Research Scientist Development Award MH01165 from the NIMH (Dr. Leuchter), the UCLA Alzheimer's Disease Center (\#P30 AG10123-05) from the National Institute on Aging, and fellowships for Dr. Holschneider from the Department of Veterans Affairs, as well as Pfizer Pharmaceuticals and the American Geriatrics Society.

\section{REFERENCES}

American Psychiatric Association (1987): Third Diagnostic and Statistical Manual of Mental Disorders, Washington, DC, American Psychiatric Press

Alema G, Sinisi L (1950): Il comportamento EEG dei soggetti affetti da tumor cerebri durante la narcosi da tiobarbiturici. Arch Psicol Neurol Psichiatr 11:390

Beaulieu C, Somogyi P (1991): Enrichment of cholinergic synaptic terminals on GABAergic neurons and coexistence of immunoreactive GABA and choline acetyltransferase in the same synaptic terminals in the striate cortex of the cat. J Comparative Neurol 304:666-680

Bickford R (1953): Some effects of barbiturate anesthesia on the depth electroencephalogram. Proc Staff Meet Mayo Clin 28:162-170

Blacklock JB, Oldfield EH, Di Chiro G, Tran D, Theodore W, Wright DC, Larson SM (1987): Effect of barbiturate coma on glucose utilization in normal brain versus gliomas. J Neurosurg 67:71-75

Brazier MAB, Finesinger JE (1945): Action of barbiturates on the cerebral cortex. Arch Neurol Psychiatr 53:51-58

Brazier MAB, Hamlin $H$, Delgado JMR, Chapman WP (1956): The persistence of electroencephalogram effects of pentothal. Anesthesiology 17:95-102

Brenner RP, Ulrich RF, Spiker DG, Sclabassi RJ, Reynolds I, CF, Marin RS, Boller F (1986): Computerized EEG spectral analysis in elderly normal, demented and depressed subjects. Electroencephal Clin Neurophysiol 64:483-492

Claridge GS, Herrington RN (1963): Excitation-inhibition and the theory of neurosis: A study of the sedation threshold. In Experiments with Drugs, New York, Pergamon, pp. 131-168

Coben LA, Danziger WL, Berg L (1983): Frequency analysis of the resting awake EEG in mild senile dementia of Alzheimer type. Electroencephal Clin Neurophysiol 55:372-380

Coyle JT, Price DL, DeLong MR (1983): Alzheimer's disease: A disorder of cortical cholinergic innervation. Science 219:1184-1190

Crane PD, Braun LD, Cornford EM, Cremer JE, Glass JM, Old- 
endorf WH (1978): Dose dependent reduction of glucose utilization by pentobarbital in rat brain. Stroke 9(1):12-18

Dierks T, Kullmann F, Engelhardt W, Maurer K (1992): Quantitative topographical analysis of effects of single thiopental bolus on human electroencephalogram. Pharmacopsychiatry 25:224-228

Duffy FH, Albert MS, McAnulty G (1984a): Brain electrical activity in patients with presenile and senile dementia of the Alzheimer type. Ann Neurol 16:439-448

Duffy FH, Jensen F, Erba G, Burchfiel JL, Lombroso CT (1984b): Extraction of clinical information from electroencephalographic background activity: The combined use of brain electrical activity mapping and intravenous sodium thiopental. Ann Neurol 15:22-30

Engel J Jr, Rausch R, Lieb JP, Kuhl DE, Crandal PH (1981): Correlation of criteria used for localizing epileptic foci in patients considered for surgical therapy of epilepsy. Ann Neurol 9:215-224

Engel J Jr, Kuhl DE, Phelps ME, Crandall PH (1982): Comparative localization of epileptic foci in partial epilepsy by PCT and EEG. Ann Neurol 12:529-537

Ferszt R, Bradac G, Nussel F (1987): Value of MRI in diagnosing Alzheimer versus vascular dementia. In Cervos-Navarro J and Ferszt R (eds), Stroke and Microcirculation, New York, Raven Press, pp 513-518

Folstein M, Folstein S, McHugh P (1975): Mini-mental state: A practical method for grading the mental state of patients for the clinician. J Psychiatr Res 12:189-198

Giswold SE, Steen PA (1985): Drug therapy in brain ischemia. Br J Anaesthes 57:96-109

Hachinski V, Lassen N, Marshall J (1974): Multi-infarct dementia: A cause of mental deterioration in the elderly. Lancet 2:207-210

Hansen LA, De'Teresa R, Davies P, Terry RD (1988): Neocortical morphometry, lesion counts, and choline acetyltransferase levels in the age spectrum of Alzheimer's disease. Neurology 38:48-54

Harris RA, Allan AM (1985): Functional coupling of gammaaminobutyric acid receptors to chloride channels in brain membranes. Science 228:1108-1110

Holschneider DP, Leuchter AF (1995): Beta activity in aging and dementia. Brain Topogr 8(2):169-180

Kiersey DK, Bickford RG, Faulconer A (1951): Electroencephalographic patterns produced by thiopental sodium during surgical operations: Description and classification. Br J Anaesthes 23:141-152

Letemendia F, Pampiglione G (1958): Clinical and electroencephalographic observations in Alzheimer's disease. J Neurol Neurosurg Psychiatr 21:167-172

Leuchter AF, Cook IA, Newton TF, Dunkin J, Walter DO, Rosenberg-Thompson S, Lachenbruch PA, Weiner $\mathrm{H}$ (1993): Regional differences in brain electrical activity in dementia: Use of spectral power and spectral ratio measures. Electroencephal Clin Neurophysiology 87:385-393

Leuchter AF, Newton TF, Cook IA, Walter DO, RosenbergThompson S, Lachenbruch PA (1992): Changes in brain functional connectivity in Alzheimer-type and multiinfarct dementia. Brain 115:1543-1561

Lieb JP, Sclabassi R, Crandall P, Buchness R (1974): Comparison of the action of diazepam and phenobarbital using
EEG-derived power spectra obtained from temporal lobe epileptics. Neuropharmacology 13:769-783

Lieb JP, Sperling MR, Mendius JR, Skomer CE, Engel J Jr (1986): Visual versus computer evaluation of thiopentalinduced EEG changes in temporal lobe epilepsy. Electroencephal Clin Neurophysiol 63:395-407

Lieb JP, Babb TL, Engel J Jr (1989): Quantitative comparison of cell loss and thiopental-induced EEG changes in human epileptic hippocampus. Epilepsia 30:147-156

Lombroso CT, Erba G (1970): Primary and secondary bilateral synchrony in epilepsy. Arch Neurol 22:321-334

Lotz P, Ballinger WI, Quisling R (1986): Subcortical arteriosclerotic encephalopathy: CT spectrum and pathologic correlation. Am J Neurorad 7:817-822

McKhann G, Drachman D, Folstein M, Katzman R, Price D, Stadlan E (1984): Clinical diagnosis of Alzheimer's disease: Report of the NINCDS-ADRDA work group under the auspice of Department of Health and Human Services Task Force on Alzheimer's disease. Neurology 34:939-944

Meyer M, Koeppe R, Frey K, Foster N, Kuhl D (1995): Positron emission tomography measures of benzodiazepine binding in Alzheimer's disease. Arch Neurol 52:314-317

Morrison J, Hof P, Campbell M, De Lima AD, Voigt T, Bouras C, Cox K, Young W (1990): Cellular pathology in Alzheimer's disease: Implications for corticocortical disconnection and differential vulnerability. In Rapoport S, Petit H, Leys D, Christen V (eds), Imaging, Cerebral Topography and Alzheimer's Disease, New York, Springer, pp 19-40

Nagata K, Tagawa K, Hiroi S, Shishido KF, Uemura K (1989): Electroencephalographic correlates of blood flow and oxygen metabolism provided by positron emission tomography in patients with cerebral infarction. Electroenceph Clin Neurophysiol 72:16-30

Oken B (1986): Filtering and aliasing of muscle activity in EEG frequency analysis. Electroencephal Clin Neurophysiol 64:77-80

Oldendorf WH, Kitano M, Shimizu S (1965): Evaluation of a simple technique for abrupt intravenous injection of radioisotope. J Nucl Med 6:205-209

Pampiglione G (1952): Induced fast activity in the EEG as an aid in the location of cerebral lesions. Electroencephal Clin Neurophysiol 1:79-82

Prichep L, Mont GF, John ER, Ferris SH (1983). Neurometric electroencephalographic characteristics of dementia. In Alzheimer's Disease: The Standard Reference. New York, Macmillan, 252-257

Román GC (1985): The identity of lacunar dementia and Binswanger's disease. Med Hypotheses 16:389-391

Román GC (1987): Senile dementia of the Binswanger type. A vascular form of dementia in the elderly. JAMA 258:1782-1788

Saletu B, Anderer P, Paulus E, Grunberg J, Wicke L, Neuhold A, Fischhof PK, Litschauer G (1991): EEG brain mapping in diagnostic and therapeutic assessment of dementia. Alzheimer Dis Assoc Dis 5:S57-S75

Schulz DW, MacDonald RL (1981): Barbiturate enhancement of GABA-mediated inhibition and activation of chloride 
ion conductance: Correlation with anticonvulsant and anesthetic actions. Brain Res 209:177-188

Selman WR, Speltzer RF, Roski RA, Roessmann U, Crumrine $R$, Macko R (1982): Barbiturate coma in focal cerebral ischemia. J Neurosurg 56:685-690

Shagass C (1953): The sedation threshold: A method for estimating tension in psychiatric patients. Electroenceph Clin Neurophysiol 6:221-233

Shapiro HM (1985): Barbiturates in brain ischemia. Br J Anaesthes 57:82-95
SPSS (1990): SPSS, Inc, Chicago, IL

Terry R, Peck A, Deteresa R, Schechter R, Horoupian D (1981): Some morphometric aspects of the brain in senile dementia of the Alzheimer type. Ann Neurol 10:184-192

Visser SL, Van Tilburg W, Hooijer C, Jonker C, De Rijke W (1985): Visual evoked potentials (VEPs) in senile dementia (Alzheimer's type) and in non-organic behavioural disorders in the elderly: Comparison with EEG parameters. Electroencephal Clin Neurophysiol 60:115-121

Wallin A, Blennow K (1991): Pathogenetic basis of vascular dementia. Alzheim Dis Assoc Dis 5:91-102 